\title{
AEROSOL TYPING BY 3-WAVELENGTH ELASTIC LIDAR SIGNALS OVER THE CENTRAL MEDITERRANEAN
}

\author{
Maria Rita Perrone*, Pasquale Burlizzi \\ Mathematics and Physics Department, Universita' del Salento, 73100 Lecce, ITALY, \\ *perrone@le.infn.it
}

\begin{abstract}
Elastic lidar signals at 355, 532, and $1064 \mathrm{~nm}$ combined with aerosol optical thicknesses (AOTs) from sunphotometer measurements collocated in space and time have been used to retrieve columnar lidar ratio (LR) values at the lidar wavelengths by a constrained iterative inversion procedure. Then, the relationships of LRs with AOTs, Ångström exponents, fine mode fractions $(\eta)$, and fine mode radii $\left(R_{f}\right)$ have been investigated for the aerosol typing. $\eta$ and $R_{f}$ values have been retrieved from a graphical framework. It is shown that the implemented methodology has allowed identifying three main aerosol types over the Central Mediterranean which are designed as urban/industrial, marine-polluted, and mixed-dust. Results on the relationships of LRs with AOTs, $\AA$, $\eta$, and $R_{f}$ for each aerosol type represent main paper results.
\end{abstract}

\section{INTRODUCTION}

The impact of aerosol on climate is widely recognized and several efforts have been undertaken to characterize aerosol optical and microphysical properties and estimate aerosol direct and indirect radiative effects. Main difficulties in quantifying these effects arise from the very high variability in time and space of the aerosol concentration. The sensitivity of aerosol direct radiative effects and heating rates (HRs) to the vertical distribution of aerosol properties has recently been investigated by one of the authors [1]. Sensitivity tests have indicated that the uncertainties on the vertical distribution of the aerosol properties may have a large impact mainly on aerosol HR vertical profiles, both in the solar and the terrestrial domain. Lidars are now days the best tools that can allow retrieving the vertical distribution of the aerosol properties. Most of the available lidar systems can only provide elastic lidar signals during daytime. As a consequence, numerical procedures only based on elastic lidar signals have been developed to characterize the dependence on altitude of aerosol properties. Ansmann et al. have proposed the singlewavelength POLIPHON (POlarization LIdar PHOtometer Networking) technique [2]. A numerical tool (LIRIC, LIdar/Radiometer Inversion Code) to retrieve vertically resolved aerosol microphysical properties by combining backscatter coefficient measurements at 3 wavelengths and sun/sky radiance measurements is described in [3]. While, a constrained iterative inversion (CII) procedure and a graphical framework (GF) is used in [4] to estimate the dependence on altitude of the aerosol fine mode radius $\left(R_{f}\right)$ and of the fine mode contribution $(\eta)$ to the aerosol optical thickness (AOT).

In this study the CII-GF retrieval scheme is applied to lidar measurements performed at a coastal site of southeastern Italy with the main goal of contributing to the typing of the Central Mediterranean aerosol. Particles from the surrounding European Countries, the African Continent, and the Atlantic Sea are advected over the Mediterranean basin. As a consequence, several studies have indicated that the aerosol direct radiative effects are among the highest in the world during the Mediterranean summers. The HYbrid Single-Particle Lagrangian Integrated Trajectory (HYSPLIT) model version 4.8, from NOAA/ARL [5], has been used to compute 96hour backward trajectories and investigate the impact of source regions on aerosol properties. A brief overview of the 3-wavelength lidar system and of the CII-GF retrieval scheme is provided in Section 2. Main results are presented and discussed in Section 3. Summary and conclusion are reported in Section 4.

\section{INSTRUMENTS AND METHODOLOGY}

The ground-based lidar system used in this study is located at the Mathematics and Physics Department of Universita' del Salento (Lecce, 
$\left.40.33^{\circ} \mathrm{N} ; 18.11^{\circ} \mathrm{E}\right)$. It is identified as UNILE (UNIversity of LEcce) lidar and operates within EARLINET since May 2000. It is nowadays it designed to derive elastically backscattered lidar profiles at $355 \mathrm{~nm}, 532 \mathrm{~nm}$ and $1064 \mathrm{~nm}$, respectively, and it is estimated to achieve full overlap between $0.5-1.0 \mathrm{~km}$ above the ground level (agl). Elastic lidar signals suffer from a need to assume an aerosol-to-backscatter ratio LR (also referred to as the aerosol-lidar ratio) to solve the ill-posed problem of the lidar equation and extract aerosol extinction and backscattering coefficient profiles. The assumption that LR is known $a$ priori is likely the largest source of systematic error within this lidar inversion procedure. However, this uncertainty can be largely reduced if an additional information, such as the AOT of the whole aerosol load, is available. A Constrained Iterative Inversion (CII) procedure which allows one to determine the aerosol extinction $(\alpha(\mathrm{z}))$ and backscatter $(\beta(\mathrm{z}))$ coefficient profiles by using as boundary conditions (1) the AOT of a selected altitude range and (2) the total backscattering coefficient $\beta_{\mathrm{T}}$ (due to molecules $\left(\beta_{\mathrm{M}}\right)$ and aerosol $\left.(\beta)\right)$ at a far-end reference height, is used in this study to reduce the uncertainties on a priori LR assumption. A detailed description of the CII procedure is provided in [4], where main benefits and limits of the CII procedure have also been underlined. AOT values at the lidar wavelengths have been retrieved from AERONET sun/sky photometer measurements co-located in space and time with lidar measurements. An AERONET sun/sky photometer operates at the UNILE lidar site since the year 2003 and it provides AOTs with accuracy of \pm 0.01 [6]. Hence, it was required that the AOTs calculated from the retrieved aerosol extinction profiles should not exceed (within \pm $0.01)$ the corresponding AOT values retrieved from co-located sun/sky photometer measurements. To this end, we have assumed that $\alpha(z)$ does not vary with altitude below the height where the lidar system achieves the full overlap. The capability of Ångstrom exponents $(\AA)$ and the spectral difference $(\Delta \AA)$ to be indicators of the dominant size of atmospheric aerosols has been exploited to estimate the dependence on altitude of fine mode fractions $(\eta)$, and fine mode radii $\left(R_{f}\right)$ from the lidar extinction profiles at $355 \mathrm{~nm}, 532$ $\mathrm{nm}$ and $1064 \mathrm{~nm}$, according to [7]. In particular, a graphical framework (GF) was developed by Gobbi et al. [7] to classify aerosol properties by the $\Delta \AA(\mathrm{z})$ versus $\AA(355,1064, \mathrm{z})$ plot. The GF provides reference points corresponding to bimodal size distributions characterized by a variety of fine mode $\left(R_{f}\right)$ and coarse mode $\left(R_{c}\right)$ modal radii combined in order to lead to prescribed fine mode fractions $(\eta)$ at $532 \mathrm{~nm}$. Angstrom coefficients at the altitude $\mathrm{z}$ have been calculated as follows:

$\AA(\lambda 1, \lambda 2, \mathrm{z})=-\ln \left[\alpha_{\lambda_{1}}(\mathrm{z}) /\left(\alpha_{\lambda 2}(\mathrm{z})\right] /[\ln (\lambda 1 / \lambda 2)]\right.$

where $\alpha_{\lambda 1}(z)$ and $\alpha_{\lambda 2}(z)$ represent the extinction coefficient at the height $\mathrm{z}$ and the wavelength $\lambda 1$ and $\lambda 2$, respectively. $\alpha_{\lambda_{1}}(\mathrm{z})$ and $\alpha_{\lambda_{2}}(\mathrm{z})$ are calculated from the following relationship:

$$
\alpha_{\lambda_{i}}(\mathrm{z})=\mathrm{LR}_{\lambda_{\mathrm{i}}} \times \beta_{\lambda_{\mathrm{i}}}(\mathrm{z}) \quad \mathrm{i}=1,2
$$

where $L_{\lambda_{i}}$ and $\beta \lambda_{\lambda i}(z)$ represent the lidar ratio and the backscattering coefficient at the wavelength $\lambda i$, respectively. The spectral curvature is represented by the difference:

$$
\Delta \AA(\mathrm{z})=\AA(355,532, \mathrm{z})-\AA(532,1064, \mathrm{z})
$$

\section{RESULTS}

A case study is analyzed, as an example, in this section to demonstrate the ability of the CII-GF technique on estimating the dependence on altitude of the fine mode aerosol contribution and the fine mode aerosol radius, on the basis of the $\AA$ and $\Delta \AA$ profiles retrieved from lidar measurements. Figure 1 shows the extinction coefficient profiles at $355 \mathrm{~nm}$ (black line), $532 \mathrm{~nm}$ (green line), and $1064 \mathrm{~nm}$ (red line) retrieved from lidar measurements performed on 5 September, 2011 from 1316 to 1343 UTC. Altitude independent LRs and AOTs calculated from the extinction coefficient profiles retrieved from the CII procedure are reported in Table 1. AOTs are in accordance within \pm 0.1 with the corresponding values retrieved from the AERONET (Lecce University) sunphotometer measurements at 1332 UTC. Figure 2 shows the pathways of the HYSPLIT analytical back trajectories referring to September 5, 2011 at 1400 UTC. They reveal that the air masses advected over southeastern Italy at $1.0,3.5$, and $4.5 \mathrm{~km}$ agl have their source region over north western Africa 
and as a consequence, they have likely been responsible for the advection of African dust particles up to $\sim 5 \mathrm{~km}$ agl. The $\AA(\mathrm{z})$ profiles that are plotted in Fig. 3a for different wavelength pairs support last comment. In fact, the $\AA$ values which are smaller than 0.7 within $1-4 \mathrm{~km}$ agl are likely due to the contribution of coarse mode particles. The spectral curvature profile is shown in Fig. 3b.

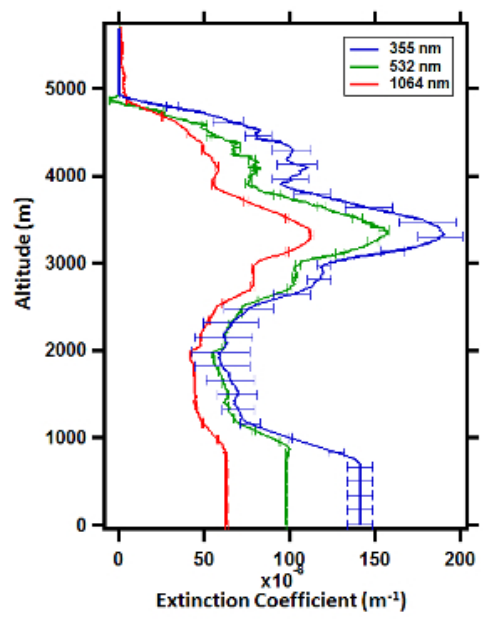

Figure 1. Extinction coefficient profiles at 355, 532, and $1064 \mathrm{~nm}$.

Calculated $\Delta \AA(\mathrm{z})$ versus $\AA(355,1064, \mathrm{z})$ values are plotted in Fig. 4 with corresponding error bars. Different colors have been used to represent $\Delta \AA(\mathrm{z})-\AA(\mathrm{z})$ values referring to different $\mathrm{z}$, as indicated by the color bar on the right of the figure. One observes that the aerosol load is

Table 1 Lidar ratios \pm corresponding standard deviations (SD) and AOT \pm uncertainties at the lidar wavelength for the September 5, 2011 study case.

\begin{tabular}{|c|c|c|}
\hline$\lambda(\mathbf{n m})$ & LR \pm 1 SD $(\mathbf{s r})$ & AOT \\
\hline 355 & $\mathbf{5 6} \pm 7$ & $0.51 \pm 0.1$ \\
\hline 532 & $\mathbf{5 8} \pm 2$ & $0.41 \pm 0.1$ \\
\hline 1064 & $48 \pm 9$ & $0.30 \pm 0.1$ \\
\hline
\end{tabular}

characterized by $\eta(\mathrm{z})$ and $R_{f}(\mathrm{z})$ values spanning the $0.50-0.70$ and the $0.14-0.24 \mu \mathrm{m}$ range, respectively. The $\AA(355,1064, \mathrm{z})$ and $\Delta \AA(\mathrm{z})$ mean values ( $\AA_{\mathrm{av}}$ and $\Delta \AA_{\mathrm{av}}$, respectively) calculated from the data points of Fig. 4 are equal to $0.4 \pm 0.1$ and $-0.2 \pm 0.2$, respectively. These values have allowed determining from the graphical framework the $\eta$ and $R_{f}$ mean values
( $\eta_{\mathrm{av}}$ and $R_{f, a v}$, respectively) which are equal to $0.54 \pm 0.04$ and $0.18 \pm 0.03$, respectively.

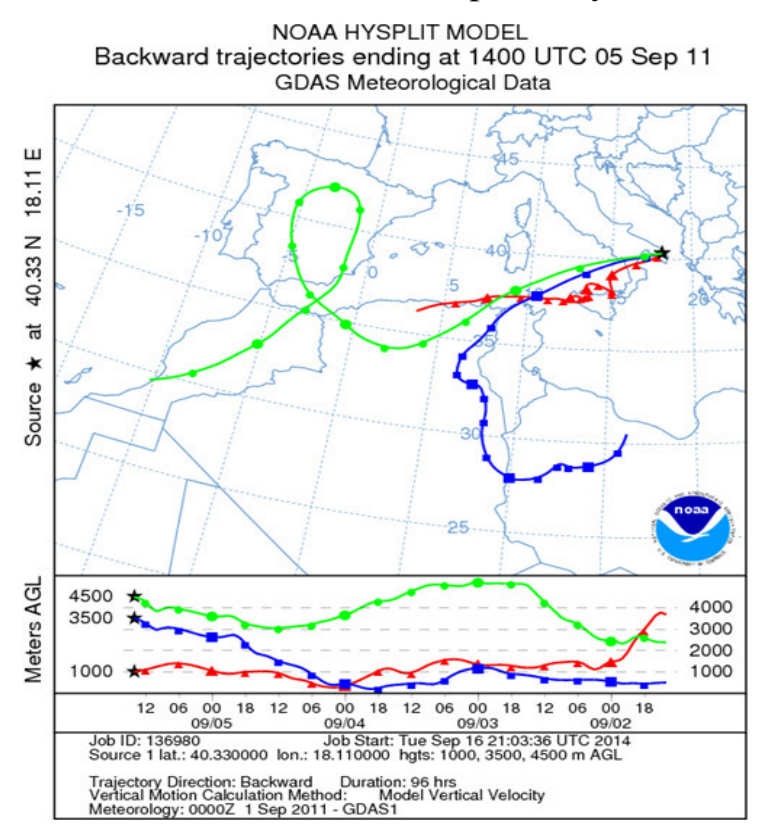

Figure 2. Pathways of analytical backward trajectories

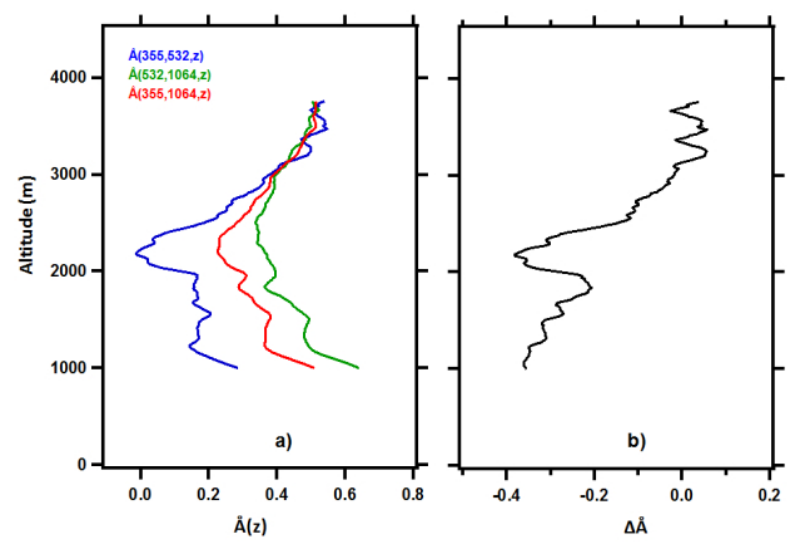

Figure 3. (a) Ångstrom exponent profiles for different wavelength pair. (b) $\Delta \AA(\mathrm{z})$ profile.

Lidar measurements performed on more than 20 days of the 2011-2014 years have been analyzed by the CII-GF scheme for typing Central Mediterranean aerosols by AOTs, LRs, backscatter color ratios, Ångström exponents, Ångström exponent spectral curvature, $\eta$, and $R_{f}$ values. Then, $\Delta \AA_{\mathrm{av}}$ and $\AA_{\mathrm{av}}$ values and the corresponding $\eta_{a v}$, and $R_{f, a v}$ have been calculated for each study case. The analysis has allowed identifying 3 main aerosol types denoted as urban/industrial (UI), marine polluted (MP), and mixed dust (MD). Table 2 shows as an example, the variability range of LR $(355 \mathrm{~nm}), \AA_{\mathrm{av}}(355$, 
$1064 \mathrm{~nm}), \Delta \AA_{\mathrm{av}}, \eta_{a v}$, and $R_{f, a v}$ for each aerosol type. One observes that from Table 2 that UI aerosols are characterized by larger values of

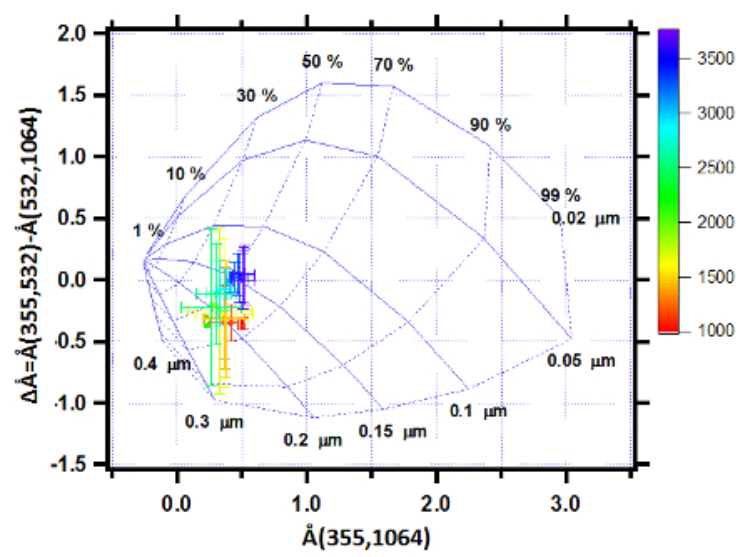

Figure 4. Graphical classification framework. Solid and dashed lines are representative of selected fine modal radii $\left(R_{f}=0.02,0.05,0.1,0.15,0.2,0.3\right.$, and $\left.0.4 \mu \mathrm{m}\right)$ and fine mode fractions at $532 \mathrm{~nm}$ of $(\eta=1,10,30,50$, $70,90,99 \%)$. Dots and errors bars represent $\Delta \AA(\mathrm{z})$ versus $\AA(355,1064, \mathrm{z})$ with corresponding standard deviations, retrieved from the lidar measurements performed on September 5, 2011 from 1317 to 1347 UTC.

LR, $\AA_{\mathrm{av}}$, and $\eta_{a v}$, for the larger presence of fine mode absorbing particles with respect to MP and MD aerosol. It has also been found that the LR and AOT spectral dependence were quite dependent on the aerosol type.

Table 2. Dependence of LR, $\AA_{\mathrm{av}}, \Delta \AA_{\mathrm{av}}, \eta_{a v}$, and $R_{f, a v}$ on aerosol type.

\begin{tabular}{|l|r|r|r|c|}
\hline & $\begin{array}{r}\text { LR(355 } \\
\text { nm) }(\mathbf{s r})\end{array}$ & $\begin{array}{r}\AA_{\text {av }}(355, \\
\mathbf{1 0 6 4})\end{array}$ & $\begin{array}{c}\eta_{a v}(\mathbf{5 3 2} \\
\text { nm) }(\%)\end{array}$ & $\begin{array}{c}\boldsymbol{R}_{f, a v} \\
(\mu \mathrm{m})\end{array}$ \\
\hline UI & $\mathbf{5 5 - 8 0}$ & $\mathbf{1 . 4 - 1 . 6}$ & $\mathbf{8 0 - 9 4}$ & $\mathbf{0 . 1 0 - 0 . 1 3}$ \\
\hline MP & $\mathbf{3 9 - 6 4}$ & $\mathbf{0 . 9 - 1 . 4}$ & $\mathbf{6 0 - 8 0}$ & $\mathbf{0 . 0 5 - 0 . 1 4}$ \\
\hline MD & $\mathbf{4 4 - 6 4}$ & $\mathbf{0 . 3 - 0 . 6}$ & $\mathbf{5 0 - 6 0}$ & $\mathbf{0 . 1 4 - 0 . 1 8}$ \\
\hline
\end{tabular}

\section{CONCLUSIONS}

The analysis of lidar measurements performed on more than 20 monitoring days characterized by advection pattern typical of Central Mediterranean, has revealed the ability of the CIIGF scheme to characterize main aerosol types by LR, $\AA(\lambda 1, \lambda 2, z), \Delta \AA=\AA(355,532, z)-\AA(532$, 1064, z), $\eta(\mathrm{z})$ at $532 \mathrm{~nm}$, and $R_{f}(\mathrm{z})$. Three main aerosol types denoted as urban/industrial (UI), marine polluted (MP), and mixed dust (MD) have been identified. Therefore, paper results have contributed to the aerosol characterization over the Central Mediterranean.

\section{ACKNOWLEDGEMENT}

This study was supported by the European Community through the ACTRIS Research Infrastructure Action under the 7th Framework Programme under ACTRIS Grant Agreement $n^{\circ}$ 262254. The authors gratefully acknowledge the NOAA Air Resources Laboratory (ARL) for the provision of the HYSPLIT backtrajectories used in this publication.

\section{REFERENCES}

[1] Perrone, M. R., Tafuro, A. M., and Kinne, S., 2012: Dust layer effects on the atmospheric radiative budget and heating rate profiles, Atmos. Environ., 59, 344-354.

[2] Ansmann, A., Seifert, P., Tesche, M., and Wandinger, U. 2012: Profiling of fine and coarse particle mass: case studies of Saharan dust and Eyjafjallajokull/Grimsvötn volcanic plumes, Atmos. Chem. Phys., 12, 9399-9415.

[3] Chaikovsky, A. et al. 2012: Algorithm and software for the retrieval of vertical aerosol properties using combined lidar/radiometer data: dissemination in EARLINET, Reviewed \& Revised Papers of the 26th International Laser Radar Conference, 25-29 June, Porto Heli, Greece, Paper SO3-09

[4] Perrone, M.R., De Tomasi, F., Gobbi G.P. 2014: Vertically resolved aerosol properties by multi wavelength lidar measurements. Atmos. Chem. Phys. 14, 1185-1204.

[5] Draxler, R.R., Hess, G.D. 1998: An overview of the HYSPLIT_4 modeling system of trajectories, dispersion, and deposition. Aust. Meteorol. Mag. 47, 295-308.

[6] Dubovik O., Holben B. N., Lapyonok T., Sinyuk A., Mishchenko M. I., Yang P., Slutsker I. 2002: Non-spherical aerosol retrieval method employing light scattering by spheroids. Geophys. Res. Lett. 29, 1415. 2

[7] Gobbi, G. P., Kaufman, Y. J., Koren, I., Eck, T. F. 2007: Classification of aerosol properties derived from AERONET direct sun data, Atmos. Chem. Phys., 7, 453-458. 